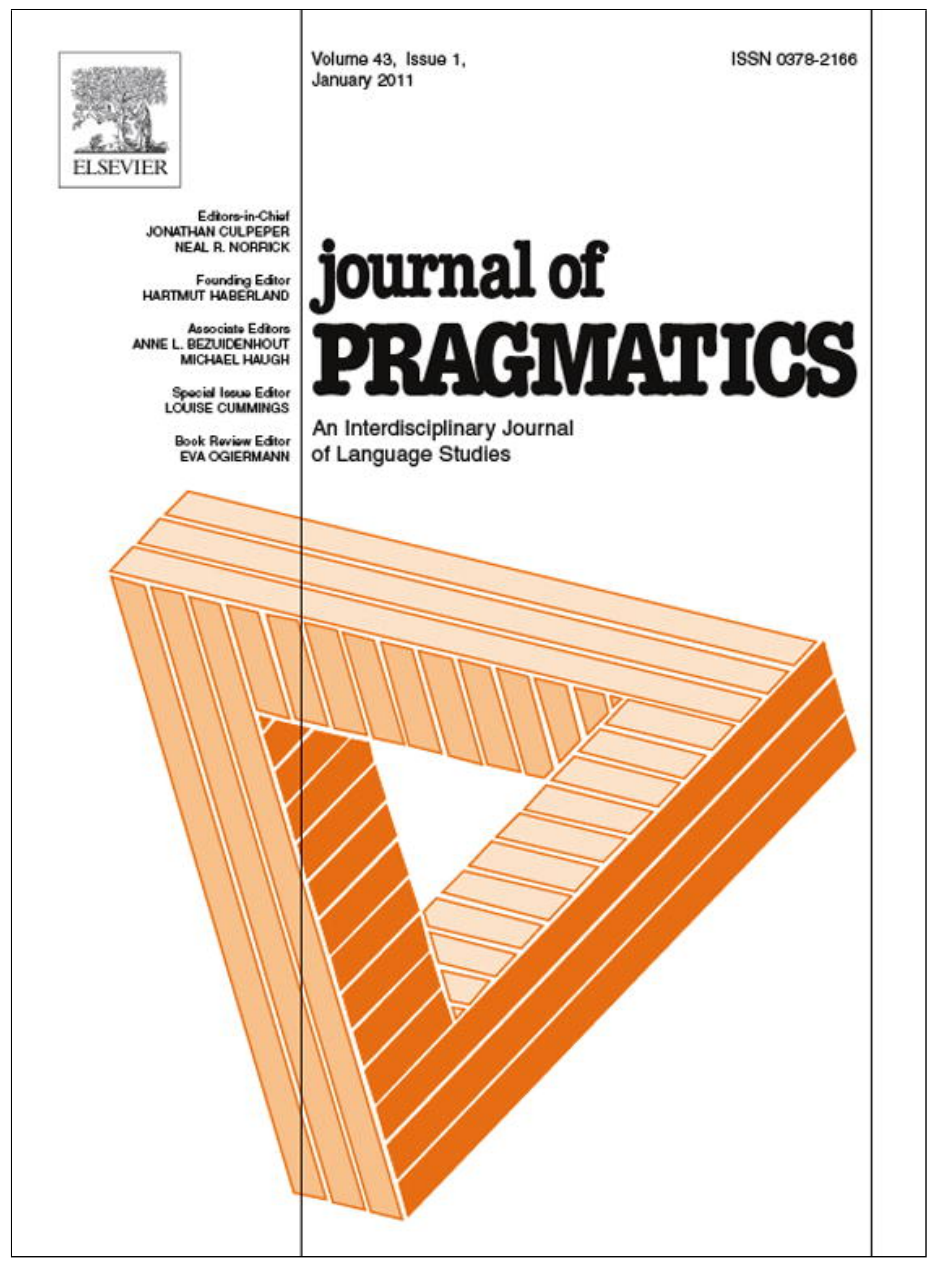

This article appeared in a journal published by Elsevier. The attached copy is furnished to the author for internal non-commercial research and education use, including for instruction at the authors institution and sharing with colleagues.

Other uses, including reproduction and distribution, or selling or licensing copies, or posting to personal, institutional or third party websites are prohibited.

In most cases authors are permitted to post their version of the article (e.g. in Word or Tex form) to their personal website or institutional repository. Authors requiring further information regarding Elsevier's archiving and manuscript policies are encouraged to visit:

http://www.elsevier.com/copyright 


\title{
Tense use in direct and indirect speech in English
}

\author{
Kristin Davidse ${ }^{a, *}$, Lieven Vandelanotte ${ }^{a, b}$ \\ ${ }^{a}$ University of Leuven, Functional Linguistics Leuven Unit, Blijde-Inkomststraat 21, PO Box 3308, B-3000 Leuven, Belgium \\ ${ }^{\mathrm{b}}$ University of Namur, English Unit (1480), rue de Bruxelles 61, B-5000 Namur, Belgium
}

\section{A R T I C L E I N F O}

\section{Article history:}

Received 13 August 2009

Received in revised form 10 July 2010

Accepted 13 July 2010

\section{Keywords:}

Direct speech

Indirect speech

Absolute tense

Relative tense

Backshift

Sequence of tense

\begin{abstract}
A B S T R A C T
This paper sets out to revisit the problem of tense in English direct and indirect speech with past reporting clauses. The general point it makes is that in all instances of speech representation, the temporal reference point defined by the 'original' speech exchange described in the reporting clause (she said, he thought, etc.) should be incorporated into the analysis of tense. It creates a second, 'surrogate' temporal zero-point within the intensional domain of the represented speaker's utterances, alongside the real temporal zero-point of the actual speaker's discourse. Recognition of this intensional domain with its own time of utterance results in an analysis of tense in the reported clause of direct speech as 'intensionally' absolute, i.e. as directly related to the time of utterance not of the actual, but of the represented speaker. Backshifted tenses in indirect speech are likewise argued to be 'intensionally' relative, involving the represented speaker's surrogate temporal zero-point which is shifted to a past time of orientation from which relations are subsequently plotted. In addition, indirect speech is shown to occur with two different types of absolute tense use: intensionally absolute tenses similar to those in direct speech, and true absolute tenses in semantically factive examples, where the tense form is related directly to the actual, not the surrogate, time of utterance.
\end{abstract}

Published by Elsevier B.V.

\section{Introduction}

Tense in represented speech ${ }^{1}$ is an area which remains curiously problematic in linguistic description. On the grammatical side, the main puzzle is often taken to be the 'backshift' (Comrie, 1986) from direct speech John said "Mary is ill" to indirect speech John said Mary was ill (Declerck, 2006:408). In contrast with the traditionally rather narrow formal focus on these phenomena, narratology in principle relates tense to differences of narrative perspective and focalisation (e.g. Fludernik, 2003), without however providing systematic analytical tools to capture these conceptual differences. What seems to be missing is a linguistic approach which correlates systematic description of the principles motivating the forms to an adequate conceptual analysis of tense in represented speech. In this paper we set out to develop such a general formfunction approach, which also elucidates backshift and issues attendant on it.

The main point we will make is that tense in represented speech, both direct and indirect, crucially involves the temporal reference point defined by the original speech act described in the reporting clause. The nature of this reference point is unique to tense in represented speech in that it is a time of utterance defined by a described situation. This claim differs from traditional assumptions in a number of ways.

\footnotetext{
* Corresponding author. Tel.: +32 163248 11; fax: +32 16324767 .

E-mail addresses: kristin.davidse@arts.kuleuven.be (K. Davidse), lieven.vandelanotte@fundp.ac.be (L. Vandelanotte).

${ }^{1}$ We thank Jacob Mey for his helpful supervision of the refereeing process. We offer particular thanks to the two anonymous referees for their very generous and incisive comments and the studies they directed us to. This added many extra dimensions to the discussion in comparison with the first draft.
} 
Firstly, it has traditionally been stressed that direct speech involves two deictic centres (Coulmas, 1986; Haberland, 1986). Direct speech is, like all utterances, related to the speech event, or 'ground' (Langacker, 1991), which is constituted by the exchange between speaker and hearer and the temporal reference point defined by this exchange. At the same time, direct speech also involves a second 'surrogate' ground (Langacker, 1985) with its own temporal coordinates, viz. the speech exchange of which the represented speaker is part. Indirect speech, by contrast, is generally assumed to have only one deictic centre, that of the actual speaker, towards which all the deictic elements of the reported utterance are claimed to be shifted (Haberland, 1986). We will argue that the represented speaker's deictic centre is also invoked in indirect speech and that it is crucial to a correct understanding of both backshifted and absolute tenses in indirect speech. Both direct and indirect speech evoke an intensional domain constituted by the represented speaker's illocutions and propositional contents, which impacts on the interpretation of the tenses used in it.

Secondly, we will argue that the temporal reference point defined by the represented speaker's speech act is different from the two types of reference points generally recognized for tenses, viz. the speaker's temporal zero-point for absolute tenses and the "situation-time of orientation" (Declerck, 2006:367) for relative tenses. The represented speaker's time of utterance combines elements of these two types of reference points in being defined by a described situation, yet creating a (second) temporal zero-point.

Neither of these points is generally recognized in linguistic descriptions of tense in represented speech, which does not only lead to interpretative impoverishment but also prevents a proper account of linguistic phenomena such as relative tense and the different absolute tense uses in indirect speech.

With these starting points, we set out to account for the various tense mechanisms found in English direct and indirect speech. To this end, we will work with, but also modify, Declerck's theory of tenses. Declerck (1991a, 1997, 2006) has developed a systematic description of absolute and relative tense use in all time zones and in various syntactic environments, including represented speech. From his work, we take the definitions and representational conventions of absolute and relative tenses, but we adapt these to the special types of absolute and relative tenses found in represented speech, for which the represented speaker's time of utterance is the reference point.

For reasons of terminological economy, we will use "speech", as in represented speech, direct speech (henceforth DS), and indirect speech (henceforth IS), as a cover term which refers not just to the representation of the content of speech, e.g. He said that ..., He asked if . . ., but also of thought, e.g. He thought that . ., He wondered if . ... Represented speech and thought can, in our view, be taken together because they pattern in parallel ways in terms of the illocutions (statements, questions, commands, offers) they can contain (Halliday, 1985:228-237). We will also use the notion of "represented speaker" as a cover term which includes the represented cognizant in represented thought.

We exclude from consideration in this article 'subjectified' forms of speech and thought representation (Vandelanotte 2006, 2009:Chapter. 8) which use a subset of the grammar of reported speech for rather different purposes. Cases in point include clauses such as I think, I guess, I mean, I say which in certain grammaticalized uses no longer serve to construe a thought or speech act, but rather to express a modal nuance ('possibly'), to hold the floor and win time for online planning ('erm'), to call the hearer's attention (as with some uses of 'I say', Brinton, 2008), and so on. Such uses no longer involve reported speech, as in them only a single speech situation is construed, towards which the subjectified clause expresses a position or attitude.

The structure of the article will be as follows. In section 2, we will set out the elements of Declerck's theory of tenses that we need as point of departure for the analysis of tense in represented speech (2.1). We will also summarize Declerck's own description of tense in represented speech (2.2). In the remainder of the article, we will argue that the deictic specificity of represented speech lies in its having temporal reference points associated with the surrogate ground of the represented speech exchange. In section 3, we will deal with tense in direct speech, arguing that in addition to the time line defined by the speaker's temporal zero-point, a second time line has to be introduced, which is oriented in function of the speaking-time of the represented utterance. In section 4 , we turn to tense in indirect speech, focusing on indirect speech constructions with a past reporting clause. We will first analyse the use of relative, or in traditional terms 'backshifted', tenses in the reported clause (section 4.1). Next, we will address the neglected issue of absolute tense in indirect speech (4.2), distinguishing between tenses that are absolute vis-à-vis the surrogate ground (4.2.2) and true absolute tenses, which have the actual ground as reference point (4.2.3).

\section{Declerck's model of tense in English}

\subsection{General lines of Declerk's tense theory}

In accordance with previous theories of tense such as Reichenbach (1966 [1947]) and Lyons (1977), Declerck views tense as a system of temporal deixis locating the situations referred to by clauses in time, taking the ongoing speech exchange as ultimate temporal reference point. As Lyons (1977:68) put it "the crucial fact about tense [...] is that it is a deictic category. A tensed proposition, therefore, will [...] contain a reference to some point or period of time which cannot be identified except in terms of the zero-point of the utterance". To this temporal zero-point, abbreviated as $t_{o}$, all situations referred to in the discourse are thus directly or indirectly related. The former is the case with absolute tenses, which are interpreted directly in relation to $t_{\mathrm{o}}$, whereas relative tenses are related to the time of orientation constituted by another situation (Declerck, 1991b:87).

Given these two types of tenses, the basic choice on introducing a new situation in the unfolding discourse is between either relating the new situation directly to the temporal zero-point of the speaker (absolute tense) and creating a new 


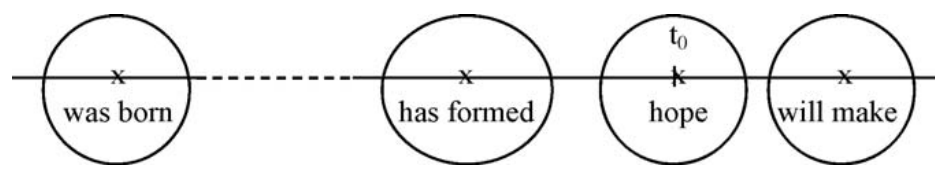

Fig. 1. Illustration of the four types of temporal domains as exemplified in (1).

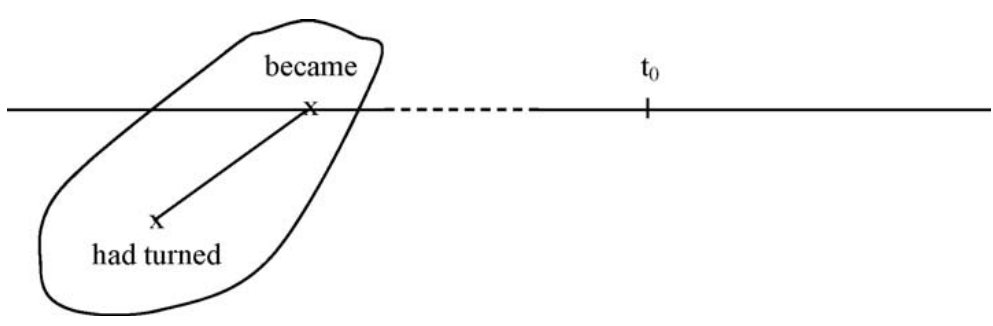

Fig. 2. Relative tense in (2).

temporal domain, or temporally relating that new situation to another situation (relative tense), i.e. incorporating it within an already established temporal domain (Declerck, 1991a, 1997, 2006).

According to Declerck, English conceptualizes time in terms of two time-spheres: the past time-sphere, located wholly before the temporal zero-point $t_{\mathrm{o}}$, and the present time-sphere, which includes $t_{\mathrm{o}}$. The present time-sphere further divides into three zones: one centering on $t_{\mathrm{o}}$ (the present zone), one lying before $t_{\mathrm{o}}$ (the pre-present zone), and one following $t_{\mathrm{o}}$ (the post-present zone). The past time-sphere and the time zones of the present time-sphere are associated with the four main absolute tenses in English. In the past time-sphere, temporal domains are established by the preterite, while the tenses establishing the three present time-sphere zones are the present perfect, the present and the future tense. Adopting the wellestablished convention of the time line (Michaelis, 2006:220), Declerck visualizes this conception of time as an oriented line on which $t_{\mathrm{o}}$ represents the temporal zero-point and the dotted line indicates that the past time-sphere does not incorporate $t_{\mathrm{o}}$. Absolute tenses are marked by crosses on the time line, where they are directly referrable to $t_{0}$. Temporal domains are represented by ovals. The four possible types of temporal domains are illustrated by example (1), ${ }^{2}$ visualized in Fig. 1.

Ewan Gordon McGregor was born 31 March 1971 in Crieff, Scotland... McGregor has formed a production company with friends Jonny Lee Miller, Sean Pertwee, Jude Law and Sadie Frost. Called Natural Nylon, they hope it will make innovative films... (http://www.imdb.com/name/nm0000191/bio)

The different linguistic meaning of relative versus absolute tenses can be illustrated with the following examples, which both contain an after-clause locating the situation referred to before that of the matrix clause.

After he had turned 60, he became a star again. (CB)

They began sleeping together just after she turned 14. (CB)

In (2) the anteriority relation is coded explicitly in the tense form: had turned 60 is a past perfect whose intrinsic meaning is the expression of anteriority vis-à-vis another past situation. The situation serving as reference point is referred to by became, which establishes a past temporal domain. Fig. 2 visualizes the meaning of the two tenses, absolute became and relative had turned. Relative tenses are represented by lines branching downward from the time line or from situations coded by other relative tenses; anteriority is symbolized by a line branching leftward (as in Fig. 2), simultaneity by a straight horizontal line, and posteriority by one branching rightward.

In (3) by contrast, the after-clause contains a preterite, which, like the matrix clause preterite began sleeping, establishes its own temporal domain. The fact that the past domain established by turned 14 is anterior to that established by began sleeping is not coded by the tense form, but is expressed by after. ${ }^{3}$ Fig. 3 visualizes these two past domains.

The intrinsic meaning of absolute tenses is thus to locate situations as past, present or future vis-à-vis the $t_{\mathrm{o}}$, whereas that of relative tenses is to express relative chronology with regard to other situations.

With these analytical tools, Declerck has developed detailed descriptions predicting how absolute and relative tenses are used in various discourse environments. In this article we will focus on cases of represented speech with a past matrix clause,

\footnotetext{
${ }^{2}$ Data in this paper are drawn either from the Internet, in which case the URL is indicated, or from the Cobuild corpus, in which case the example is followed by (CB). Examples from the Cobuild corpus were obtained via remote log-in and are reprinted here with the kind permission of HarperCollins publishers.

${ }^{3}$ The chronology of situations referred to by absolute tenses can also be deduced on the basis of other semantic or pragmatic information than that conveyed by temporal connectives, such as temporal adverbials or world knowledge about the sequence of events.
} 


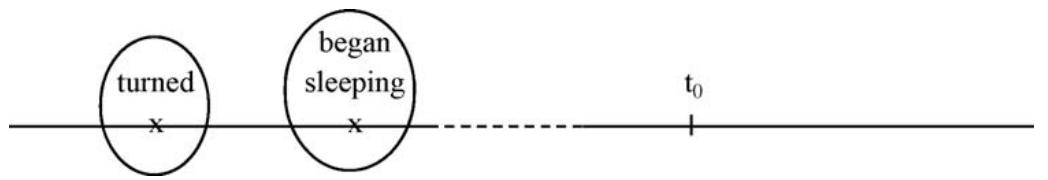

Fig. 3. Absolute tense in (3).

as these will allow us to set out the main mechanisms that are involved. Therefore, we will in the remainder of this section review Declerck's analyses of tense use in the past time-sphere only.

Within a past domain, temporal relations between represented situations are coded as follows. Anteriority is expressed by a past perfect ('past in past' according to Halliday (1985:180)), had been in (4), and posteriority by the tense form with would referred to as 'future in past' by Halliday (1985:180), would become in (5). That these two tenses intrinsically invoke another past situation as reference point, i.e. that they are relative, is generally accepted in the literature.

(4) They were nearly ready. Two small teams had already been in and out of Iran to scout the landing site at Desert One. (www.theatlantic.com/doc/200605/iran-hostage)

... after completing the necessary formalities, he was duly accepted as a "Postulant" member for two years, after which he would become a full member. (www.witheridge-devon.com/crier.htm)

Simultaneity vis-à-vis a situation in a past domain is, according to Declerck, expressed by a relative past. Both the existence and status of the relative past tense have been debated (see e.g. Salkie and Reed, 1997; Boogaart, 1996). It appears incontestable that the English preterite, in an example like (6) for instance, receives a relative reading (Boogaart, 1996:217). However, like Huddleston (1989:336), we will treat the relative reading as deriving from the more basic absolute reading due to contextual factors, rather than positing two preterites with two different linguistic meanings (see also section 4 below). Was following up in (6) is such a preterite with a pragmatically inferrable relative reading.

Just prior to the killings, Horn had begun working for the Swan Land and Cattle Company. He had killed the two rustlers, Matt Rash and Isom Dart, while he was following up on what became known as the Wilcox Train Robbery... (http://en.wikipedia.org/wiki/Tom_Horn)

As indicated by the subordinator while, was following up is simultaneous with the past situation in the matrix clause had killed. This matrix clause is part of a narrative sequence in the past perfect (cf. had begun working), which makes it impossible to interpret was following up as an absolute past tense co-occurring with other preterites.

In example (7), by contrast, was and gave both receive absolute readings referring to past situations which, as transpires from the context, temporally coincide.

I was thirsty, and you gave me to drink. (Matthew 25:35)

Preterites with absolute readings can also refer to past situations with a non-simultaneous relation to other past situations. Served in (8) denotes a situation anterior to 'his death came', while learned in (9) refers to a situation posterior to she became suspicious and questioned B.R.K. That the 'real-world' chronological relations between the preterites in (8) and (9) are cases of anteriority and posteriority respectively is confirmed by the fact that the preterites in the subordinate clauses can be replaced by the relative tenses had served in (8) and would learn in (9).

This Marine's death came after he served in Iraq (www.startribune.com/local)

She became suspicious and questioned B.R.K. about the incident, after which she learned they had engaged in oral sex. (bulk.resource.org/courts.gov/states/Tex.App.07)

In short, situations are located relative to a situation in a past domain by a past perfect (anteriority), a relatively construed preterite (simultaneity) and a future in past (posteriority), while locating situations absolutely in a past domain-leaving their chronology vis-à-vis other situations to be inferred contextually-involves (absolutely interpreted) preterites only.

\subsection{Declerck's analysis of tense in reported speech}

With regard to represented speech, Declerck (e.g. 1999) has always stressed that the tenses in the reported clauses can be analysed as relative or absolute in exactly the same sense as defined above and that no special mechanisms need be invoked for their analysis. The system for expressing anteriority, simultaneity and posteriority between an indirectly reported utterance and a past reporting verb is claimed to be exactly the same as that used to represent a situation as happening before, after, or at the same time as another past situation. For instance, the relation of anteriority between the head clause and the adverbial time clause in (2) above (Declerck, 2006:643) and that between the reporting and reported clause in (10) 


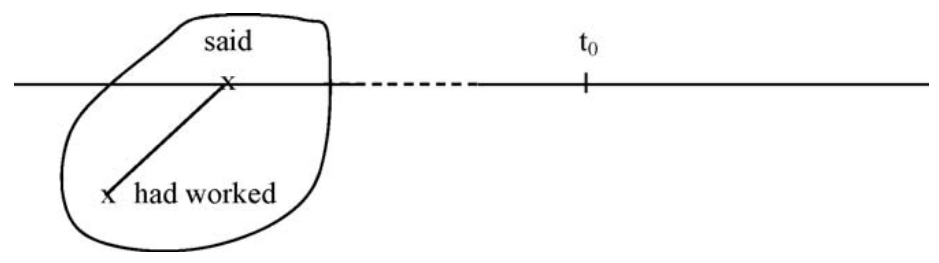

Fig. 4. Declerck's (2006:373) analysis of tense in indirect speech.

(Declerck, 2006:373) are treated in exactly the same way and represented with the same diagrammatic conventions, as shown by the analyses of examples (2) and (10) visualized in Figs. 2 and 4 respectively.

$$
\text { John said that he had worked all day (Declerck, 2006:373) }
$$

In the literature, analyses of indirect speech examples such as (10) have generally been couched in terms of the temporal relation between the two situations referred to, the saying event and the reported situation (e.g. Huddleston, 1989:337; Boogaart, 1996:217). In other words, tense in reported speech has been dealt with in just the same way as tense in any two combined clauses such as head clause and adverbial clause, or antecedent clause and relative clause.

By contrast, Vandelanotte $(2002,2005,2009: 80-104)$ has argued that in order to do justice to the specificity of tense in represented speech, an analysis has to be developed which incorporates a second temporal zero-point, viz. the 'surrogate' $t_{\mathrm{o}}$ associated with the represented speaker. It is widely recognized that any form of speech representation crucially involves the distinction between the actual speech situation and the represented speech situation (e.g. McGregor, 1997:152; Janssen, 1996:244). What has received less attention is that both of these also define a time of utterance, a temporal zero-point: the real $t_{\mathrm{o}}$ of the actual speaker and the surrogate $\mathrm{t}_{\mathrm{o}}$ associated with the represented speaker. To analyse tense in represented speech, we have to account not only for the temporal relation between the saying event and the reported situation, but we also have to elucidate how the tenses relate to the real $t_{\mathrm{o}}$ and the surrogate $t_{\mathrm{o}}$. Haberland $(1986: 221,249)$ is one study that does conceptually distinguish between "the speaking point-of-time" of the actual speaker and of the represented speaker. ${ }^{4}$ This study does not deal in detail with tense in English represented speech, but its conception of both direct and indirect speech includes the actual speaker's $t_{\mathrm{o}}$ and the represented speaker's $t_{\mathrm{o}}$. We will indicate similarities and differences with Haberland's approach, when, in the rest of this paper, we set out the specifics of our analysis of tense use in direct and indirect speech in English.

\section{Tense in direct speech}

The deictic dualism of represented speech is most obvious in direct speech (DS), in which a complete 'deictic shift' takes place from the actual speaker's to the represented speaker's deictic centre and the represented speaker's deictic centre is fully operative. The consequence of this, we argue, is that tenses are plotted directly vis-à-vis the two distinct temporal zeropoints of the reporting and the reported clause. ${ }^{5}$

The plausibility of this claim can best be shown in examples in which the situation in the reported utterance is simultaneous with the act of speaking described by the matrix clause, e.g. (11).

Nadia Grey, 21, of Buxton Road, said: "I'm currently looking for a house with my sister and it will cost us a fortune.” (www.macclesfield-express.co.uk/news/s/1035333_anger_over_sir_nicks_expenses_claims)

If both absolute tenses were related to the actual speaker's $t_{\mathrm{o}}$, then the described speech act (said) would have to be situated earlier in time than the situation of the reported utterance ('m looking for), which would have to be located in the present time zone. This, of course, would be nonsensical. Yet, one is led to such illogicality if one does not recognize the different deictic centres invoked by reporting and reported clause. In the reporting clause, the relevant $t_{\mathrm{o}}$ is that of the speaker within the actual speech situation, whereas in the deictically shifted reported clause, situations are located vis-à-vis the represented speaker's $t_{0}$. The present tense 'm looking for is not located at the actual speaker's $t_{\mathrm{o}}$, but at the represented speaker's $t_{\mathrm{o}}$, which is evoked by Nadia Grey said. This second $t_{\mathrm{o}}$, which we will standardly refer to by the abbreviated form $t_{\mathrm{o}(\mathrm{RS})}$, is inherently evoked by the fact that Nadia Grey said represents a speech exchange. In DS the $t_{\mathrm{o}(\mathrm{RS})}$ is dramatically reenacted (Haberland, 1986:220) as the 'speaker-now' (Halliday, 1985:75) of the reported utterance. It is a fully operative deictic centre to which tenses in the reported clause relate deictically, i.e. absolutely. As Haberland (1986:221) puts it for a case like (11), "In order to refer to actions, states etc. occurring or obtaining at the speaking-time of the model [the represented utterance, K.D. \& L.V.] they [speakers, K.D. \& L.V.] employ the tense used to refer to actions and states occurring or obtaining at the point-of-time of speaking".

\footnotetext{
${ }^{4}$ We thank one of the anonymous referees for directing us to Haberland (1986) as an essential reference.

${ }^{5}$ While devoting little explicit attention to tense use in the reported utterances of direct speech, Declerck (2006:390) does not single out the absolute tenses found in them as differing in any way from absolute tenses in other grammatical environments.
} 
The nature of the surrogate $t_{o}$ can be clarified by the recognition that represented speech acts create what Rigter (1982) has called 'intensional domains' in the discourse, i.e. domains of interpretation with their "own set of presuppositions and truth conditions, in terms of which propositions can be evaluated and interpreted" (1982:96). Whereas Rigter defines intensional domains in truth functional terms, we propose a speech functional definition of intensional domains in represented speech. ${ }^{6}$ Not only the propositional content but also the illocution (e.g. statement or question) fall under the represented speaker's responsibility (Dik, 1997:96-105). For instance, with a reported question such as (12)

$$
\text { John asked: “when will Lexicon drop production on it?” (www.loopers-delight.com/LDarchive/LDarchive) }
$$

what is at stake is not whether 'when will Lexicon drop production on it' was true in the represented speaker's past intensional domain. Rather, the crux is whether it is the represented speaker, John, who is responsible for asking that question. In other words, our notion of intensional domain attributes both the illocution and the propositional content with all its presuppositions to the represented, rather than the actual, speaker. Intensional domains are not just created by reported statements, but by the full array of illocutions that can be reported, including questions and commands.

Some adverbial clauses, such as clauses of purpose and reason, also create a sort of intensional domain. ${ }^{7}$ Clauses of purpose and reason form a special type of adverbial clause, distinct from the otherwise similar adverbial clauses of result and cause in that the former, like reported speech, represent the consciousness of the agent of the head clause (Verstraete, 2008:779). The reason why or the purpose for which the agent carries out the act described in the head clause is 'projected' (Halliday, 1985:196-198) through the consciousness of that agent. It contains that agent's, not the speaker's, propositions and the propositional attitudes and presuppositions are also those of the described agent (Verstraete, 2008). This can be illustrated with the purpose clause in (13).

$$
\text { God sent his only Son into the world, so that we might live through him. (1 John 4:9) }
$$

Both the proposition and the propositional attitude expressed by the modal might have to be referred to God, not the actual speaker. However, unlike with the intensional domains of represented speakers, such clauses may allow less room for incorporating the described agent's illocutions. For instance, a purpose clause cannot be a question, even though this is not excluded with a reason clause, as illustrated by (14).

So she got really pissed because couldn't he just eat dairy, fish and meat for 1 time as well? (bobobaroque. blogspot.com/2010/03/planet-arora-heap.html)

In more cognitive-linguistic terms, one could say that reporting clauses create intensional mental spaces (Fauconnier, 1985) distinct from the actual speaker's mental space and 'fictive' (Langacker, 1999, 2005) ${ }^{8}$ with regard to it. In DS the representation of the reported utterance is fictive in that it is being dramatically re-enacted ${ }^{9}$ in contrast with the reporting clause which is constructed at the ongoing moment of encoding. It is this re-enactment of the reported utterance that creates in the intensional domain of DS a $t_{\mathrm{o}(\mathrm{RS})}$, which is a second speaker-now, if only dramatically and fictively. The fictivity of this second 'now' is particularly obvious if the speech situation being reported is located in the past, as in (11). Tenses that are absolute vis-à-vis the represented speaker's $t_{\mathrm{o}(\mathrm{RS})}$ we will call "intensionally absolute" tenses, as opposed to those that are true absolute tenses vis-à-vis the actual speaker's $t_{\mathrm{o}}$.

In order to represent this analysis of tense in DS diagrammatically, it is necessary to enrich Declerck's diagrams with a second time line oriented in function of the $t_{\mathrm{o}(\mathrm{RS})}$, as in Fig. $5,{ }^{10}$ which represents the analysis of example (11). On this representation we can visualize that DS involves two deictic centres which both function as speaker-now of absolute tenses, the current $t_{o}$ of the actual speech situation and the fictively 'current' $t_{\mathrm{o}(\mathrm{RS})}$ invoked by the represented speech situation. We indicate that this fictively current $t_{\mathrm{o}(\mathrm{RS})}$ is co-temporal with the situation-time of the reporting clause by means of a dotted vertical line. The diagram also visualizes the relative chronology of the reporting situation and the reported situation, which is one of simultaneity in (11).

We now turn to examples in which the situation in the reported utterance is not simultaneous with the described speech act, as in for instance (15)-(16).

The Abbé de Sieyès was asked what he had done during the terror that followed the French revolution. "I survived," he said. (The Economist, 'Li Yuqin (Obituary)', 10 May 2001)

John said: “I will report it stolen.” (folk.uio.no/hhasselg/grammar/week8_ch7a.htm)

\footnotetext{
${ }^{6}$ Rigter's notion of intensional domain was first applied to the represented speaker's discourse in Declerck and Tanaka (1996), who took over his truth functional approach.

7 Many thanks to J.C. Verstraete (p.c.) for pointing this out to us.

${ }^{8}$ Langacker (1999:78) characterizes fictive conceptualizations evoked by linguistic predications as "departures from the direct description of ACTUALITY".

9 But, as correctly pointed out by Haberland (1986:220), not really performed.

${ }^{10}$ Haberland (1986:249) offers no visual representation of tense in DS. However, his diagram of tense in IS contains only one time line (see also footnote 13).
} 


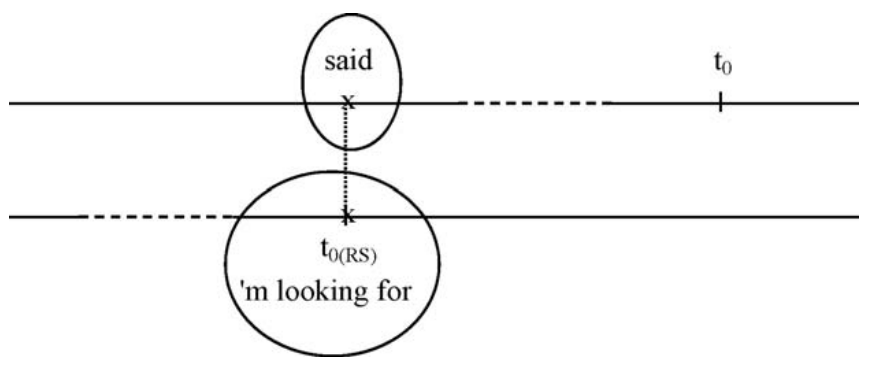

Fig. 5. Tense in direct speech with present tense reported clause.

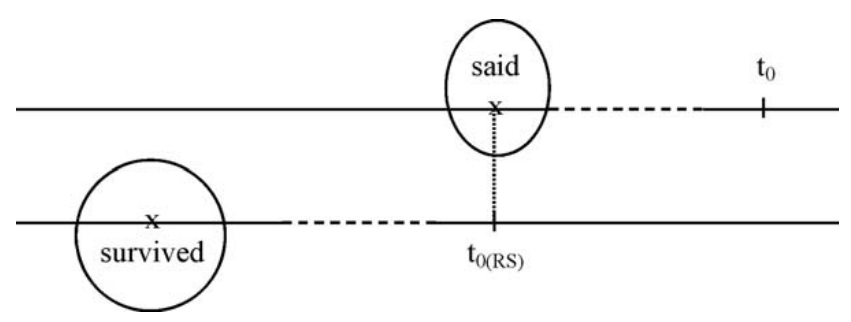

Fig. 6. Tense in direct speech with past tense reported clause.

The reasoning against an analysis in terms of a single time line set up for example (11) above can be extended to examples such as (15)-(16). For instance, in (15) survived is not simply a past situation on a par with said. These two situations cannot be conceptualized as being linked by a simple relation of succession within the past time-sphere defined by the actual $t_{\mathrm{o}}$, because the two situations belong to different mental spaces, that of the actual speaker and the intensional domain associated with the represented speaker. It is not the past situation-time constituted by he said that survived is past to. Rather, survived is past vis-à-vis the fictively current speaker-now of the represented utterance, the dramatically re-enacted surrogate $t_{\mathrm{o}(\mathrm{RS})}$ invoked by he said. Fig. 6 visualizes this analysis.

\section{Tense in indirect speech}

The traditional treatment of tense in indirect speech (IS) (e.g. Huddleston, 1989:335, Boogaart, 1996:217, Declerck, 2006:408-412) is typically set out with an example such as (17).

$$
\text { John said that Mary was ill. (Declerck, 2006:408) }
$$

The two possible readings of (17) are taken to differ only with regard to the question whether the reported situation coincides with (18a) or precedes (18b) the reporting clause situation.

$$
\text { John said Mary was ill (as he was speaking). }
$$$$
\text { John said Mary was ill (ten days ago). }
$$

In the first case, Declerk analyses was as a relative preterite expressing simultaneity with the reporting clause. In the second reading, he analyses was as an absolute preterite, which, as Boogaart (1996:218) observes, is claimed to create "its own domain in the past relative to the moment of speech, and irrespective of the temporal location of another situation such as, in indirect speech, the situation presented in the matrix clause". ${ }^{11}$ Regarding the two preterites posited by Declerck, Boogaart formulates the, in our view, correct general criticism that it is not until we know on the basis of contextual information whether the reported situation is simultaneous with or anterior to the reporting clause situation that we can attribute the labels "absolute" or "relative" to the preterite. For this reason, Boogaart (1996:218) argues, it is impossible to maintain that in (18a) the past form "expresses" simultaneity with the reporting clause, whereas in (18b) it "expresses" a direct relation of anteriority to the $t_{0}$. It therefore appears more accurate to view the 'past vis-à-vis the moment of speech' meaning as the basic one, from which the relative reading ('simultaneous with a past situation') derives in specific contexts. Moreover, we will argue in the next section that the very concepts of 'absolutely' or 'relatively' construed tenses in IS have to incorporate the represented speaker's deictic centre because they occur in the represented speaker's intensional domain.

\footnotetext{
${ }^{11}$ In connection with Boogaart's point, it will be recalled that, in section 3, we have related the surrogate $t_{\mathrm{o}(\mathrm{RS})}$ of absolute tenses in directly reported utterances to the temporal location of the matrix clause.
} 


\subsection{Intensionally relative tense in indirect speech}

As shown by examples (19)-(21), IS uses the same set of tenses which express anteriority, simultaneity and posteriority between temporally connected situations in a past domain (see e.g. (4)-(6) above), viz. the past perfect, the present and the future in past, to convey at first sight roughly similar temporal relations between the reporting and reported clause.

$$
\begin{aligned}
& \text { John said he had asked his staff to address the issue. } \\
& \text { (www.brattleboro.org/.../uploads/\%7BDB673CD1-56AC-4A71-A5A6-CE7F95EAF56C\%7D.PDF) }
\end{aligned}
$$

At one point, John said that he was suffering from a cold and was about to lose his voice. (www.filmarcade.net/2008/06/john-carpenter-tribute-at-aero-theater_16.html)

John said that he would provide hard copies of his proposal to the Committee. (https://www.airquality.nh.gov/rivers/rmac/941123MIN.htm)

However, when looked at more closely, fundamental differences appear between the temporal reference points and relations invoked by this set of tenses in IS and in non-reported discourse. This is due to the fact that the matrix clauses in (4)-(6) are descriptions of states of affairs whose temporal location constitutes as such the reference point for the tense dependent on them. For instance, in (5) the past location of the preterite in the matrix clause (was started) provides as such the time of orientation of the relative tense would get better. By contrast, the matrix clauses in (19)-(21) describe speech acts, which define two reference points, their temporal location and the surrogate ground of the reported utterance. In (21) it is not simply the past location of John said as such with regard to which would provide is posterior. Rather, would provide is posterior with regard to the surrogate ground invoked by the reporting speech situation. Would provide conveys the represented speaker's future intended act at the time of the speech exchange represented by John said. If the concepts of absolute and relative tense, temporal zero-point and situation-time are meant to capture the deictic-temporal structure of tense uses, then the posteriority conveyed by would provide must in some way be related to the represented speaker's deictic centre, despite reflecting the actual speaker's past reporting perspective.

As we find the set of tenses expressing relations of anteriority, simultaneity and posteriority here (examples (19)-(21)), it is clear that the surrogate ground is not, unlike in DS (see examples (11)-(12) and (15)-(16)), activated as a (fictively) 'present' $t_{o(R S)}$. In some way, the surrogate ground in these examples has undergone a shift into a 'past' time of orientation. We will therefore argue that the traditional notion of 'backshift', which refers to the mechanism leading from absolute tenses in DS to the relative tenses in IS, involves a shift from a present $t_{\mathrm{O}(\mathrm{RS})}$ to a past time of orientation. This reflects the deictic dependence of the indirectly reported utterance on the past reporting clause, but does not prevent the surrogate ground from remaining present as interpretative reference point. In indirect speech, the represented speaker's intensional domain is also present. It is to the represented speaker that we refer the propositional contents of the reported utterance as well as the illocutions, which in English are realized by distinct formal complement types (Dik, 1997:100-101).

Even in person reference in English IS, reflexes of the represented speaker's deictic centre are found. As is well known, the person deixis of the reported clause in IS is geared to the actual speaker's deictic centre. ${ }^{12}$ At the same time, it has been noted both within formal (Huang, 2007:266-270) and cognitive-functional (Van Hoek, 1997) frameworks that the represented speaker's deictic centre also plays a crucial role in the person deixis in IS, not only in the general semantic interpretation, but also as a necessary explanatory factor of some otherwise unexplainable mechanisms. The use of logophoric reflexives illustrated in (22), for instance, can only be explained by invoking the represented speaker as 'utterer' of the reported utterance.

$$
\mathrm{John}_{1} \text { said that the article was written by Ann and himself } 1 / \text { him }_{1} \text {. (Van Hoek, 1997:176) }
$$

Speaking about John 1 , Peter said that the article was written by Ann and *himself $1 /$ him $_{1}$. (Van Hoek, 1997:176)

As pointed out by Van Hoek (1997:176), himself refers logophorically to John, the 'utterer' of the reported statement. Himself reflects John's internal point of view, i.e. the conception of himself as viewed from his own perspective (Van Hoek, 1997:176). By contrast, logophoric himself is not possible in (23), as John is not the represented speaker of a reported utterance.

Analogously, in the field of temporal deixis, the use of speaker/hearer-oriented modals such as must in IS with past reporting clause invokes the presence of the represented speaker as 'utterer' in the surrogate ground. An example such as (24) illustrates this phenomenon, which from the point of view of the general tense properties of must appears anomalous (Declerck, 1991b:384).

Then all of a sudden she pulled herself together and rushed into one of the rooms where there was a safe. It was standing wide open and there wasn't a thing in it. Then she became perfectly calm and said that we must call the police at once. (CB)

\footnotetext{
${ }^{12}$ The deictic dependence of person reference on the reporting clause is more stringent than that of tense, as the former is obligatory, while relative tense is only the unmarked option.
} 
Must is well known not to have a past form, in contrast with, for instance, have to (Declerck, 1991b:384), whose use in IS with past matrix is illustrated in (25).

(25) Harry finished the pint of Smithwick, and before he could leave, another pint was put down in its place; and though he said that he had to be going, the men insisted that he remain. (CB)

Yet, in an IS example such as (24), must receives a relative past reading like had to in (25), reflecting the actual speaker's past reporting perspective. Similarly, might in IS is a relative past with a simultaneity relation to the past reporting clause in (26). Interpretatively, it conveys 'may' at the represented speaker's $t_{\mathrm{o}}$.

Yes, Papa said you might have the boat if you wanted it.

(http://www.online-literature.com/laura-richards/the-merryweathers/5/)

Semantically, the specificity of the normally non-tensed must and may lies in their typically expressing that the source of the modality is the speaker - or the hearer in interrogatives (Declerck, 1991b:369, 381). They do not describe objectively existing obligations or permissions. Rather, they are concerned with the hic et nunc issuing by the speaker of obligation and permission (Verstraete, 2001). They involve 'performative' (Nuyts, 2005) uses of modality to which the speaker as source of the modality is central. This is why relative past must and might can only be used within intensional domains invoking the speech or mental state of a represented agent: indirect speech, as in (24) and (26), or adverbial clauses creating an intensional domain, as in the purpose clause in (13) above, God sent his only Son into the world, so that we might live through him. When they are used in IS, as in (24) and (26), performative modals must and might convey that the represented speaker is the source of the modality. This extension of their normally non-tensed use enables the expression of the subjective, speakerrelated, type of modality in past reported clauses such as (24) and (26). In this relative past use, they are instances of backshift. As such, they clearly illustrate the view of the backshift mechanism being proposed here. Their speaker-related semantics cannot be explained without referring to the represented speaker of the surrogate ground. At the same time, they also illustrate how, as backshift involves temporal dependence on the past matrix, the surrogate ground is not fully operative in the same way as in directly reported utterances, but is shifted to a past time of orientation. This analysis differs from the traditional understanding of backshift in that we do not view the past speech event described by the matrix as reference point of the relative tenses in the reported utterances, but the surrogate ground invoked by it, which is shifted into a past time of orientation.

How should this shift from the $t_{o}(\mathrm{RS})$ be conceived of? As shown by Declerck (1991a,b, 2006), shifts of the temporal reference point binding relative tenses are found elsewhere in the English tense system. One example is the shift from a present perfect to a past time of orientation binding a preterite in terms of simultaneity (Declerck, 2006:461-462), as in

I've never seen an oil spill that was so badly controlled. (example heard on the BBC news)

The present perfect' ve never seen assesses the occurrence of the predicate in a time span starting in the past and going up to the time of speaking. However, as a reference point for the tense in the subordinate clause, this present perfect is shifted into the past time-sphere (with no link to the $t_{\mathrm{o}}$ ). As a (shifted) past reference point, it licences the use of the tense forms expressing domain-internal relations in a past domain, such as the past was controlled to express simultaneity. Semantically, however, was controlled is simultaneous with the present perfect' ve never seen, which implies a period up to $t_{\mathrm{o}}$. This shift is visualized in Fig. 7.

The shift from pre-present situation-time to past time of orientation is represented on the second time line, which, as a mechanism interior to the domain established by' ve never seen, is enclosed completely within that domain.

The shift from the surrogate $t_{\mathrm{o}(\mathrm{RS})}$ to a past time of orientation in the IS examples (19)-(21) is a very comparable mechanism. The original reference point of the tenses in the reported utterances is the $t_{\mathrm{o}(\mathrm{RS})}$ in the surrogate ground. In accordance with the deictic dependence of the indirectly reported utterance on the past reporting clause, it is shifted into the past time-sphere. As a past reference point, it sanctions the use of the system for expressing temporal relations within a past

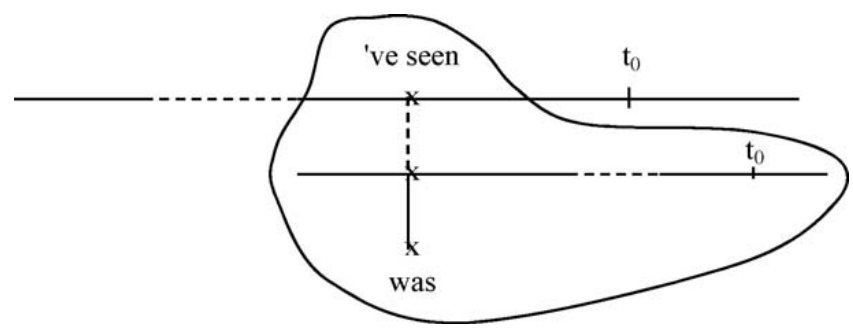

Fig. 7. Shift from a present perfect to a past time of orientation. 


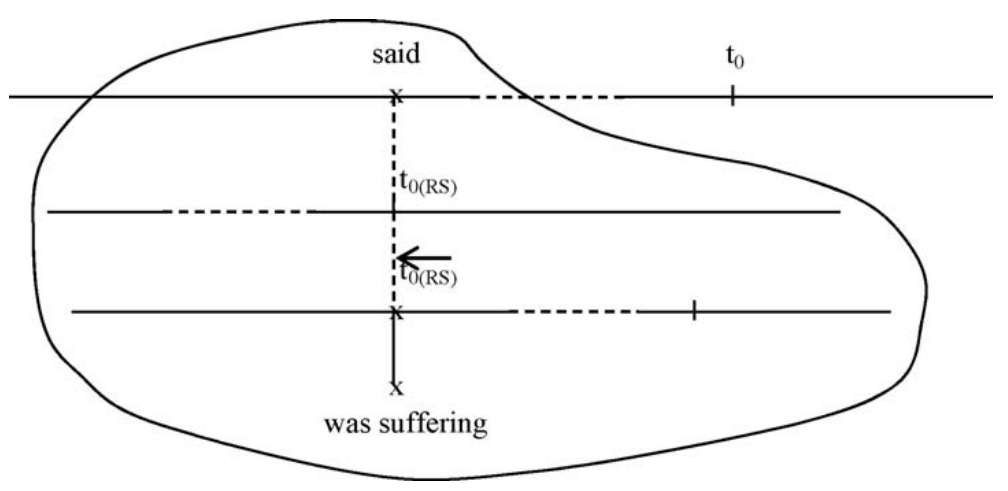

Fig. 8. Intensionally relative tense in indirect speech.

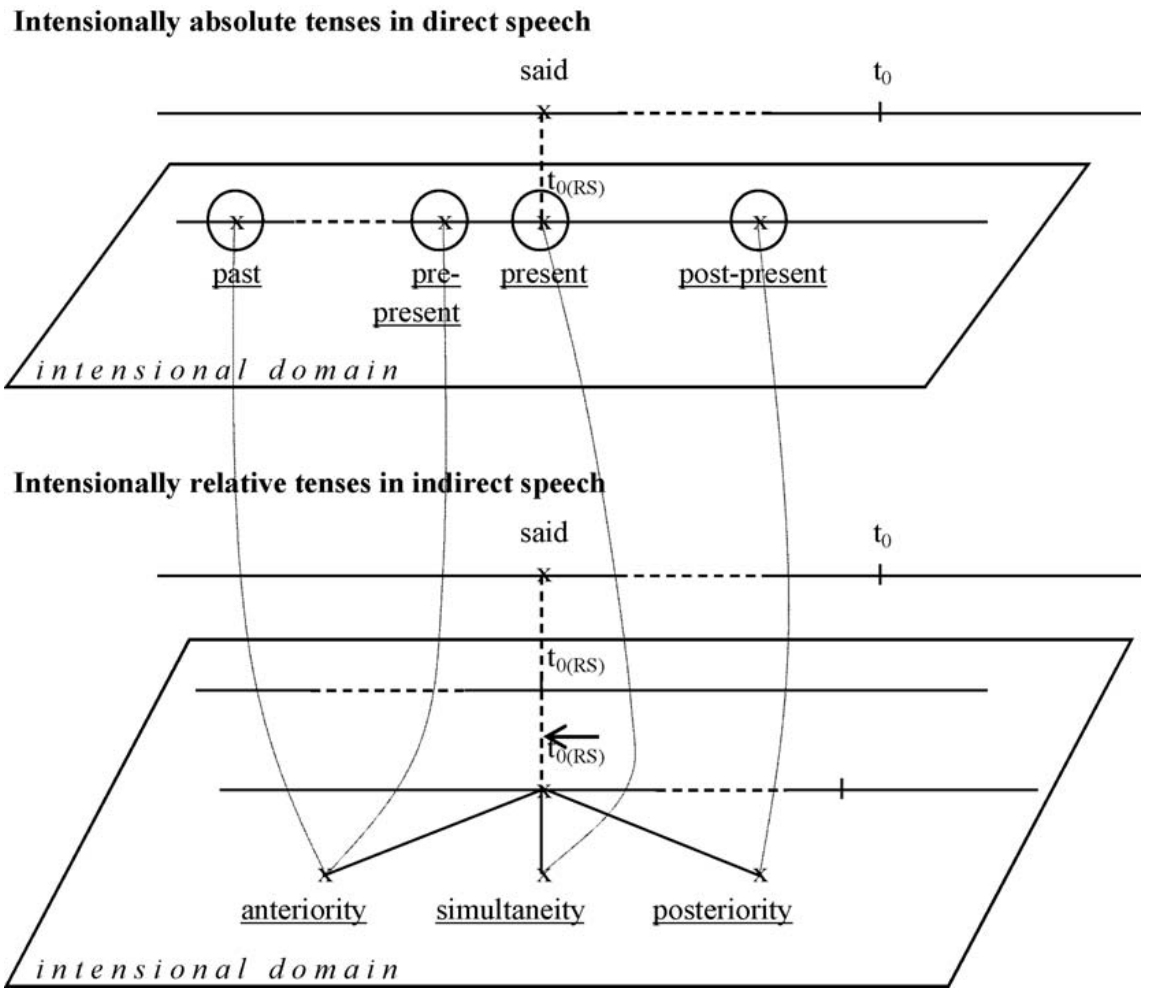

Fig. 9. The mechanism of backshift.

domain. But it remains the reference point of an intensional domain, constituted by the represented speaker's propositional

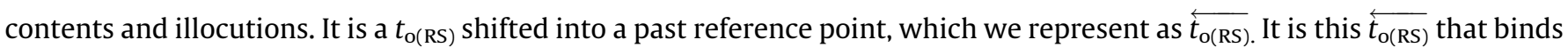
the relative tenses of the reported utterance. Fig. 8 visualizes the proposed shift for example (20), John said that he was suffering from a cold, with the same conventions as used for the shift from pre-present to past reference point in Fig. 7.

This figure also visualizes the relative chronology between the represented speech situation and the situation described in the utterance. In (20) this is a relation of simultaneity, mediated by the $\overleftarrow{t_{\mathrm{o}(\mathrm{RS})}}$. Fig. 8 visualizes (i) the co-temporality of the $t_{\mathrm{o}(\mathrm{RS})}$ with the past time of the reporting clause, (ii) the shift of this $t_{\mathrm{o}(\mathrm{RS})}$ into a past time of orientation in the intensional domain, and (iii) the way in which the relative tense was suffering relates to this backshifted $t_{\mathrm{o}(\mathrm{RS})}$. As backshifted relative

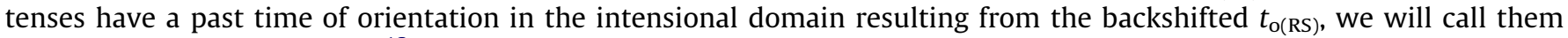
"intensionally relative" tenses. ${ }^{13}$

We can now give an overview, visualized in Fig. 9, of the complete phenomenon of backshift from DS to IS with past reporting clause. As we have argued, backshift is all about explaining the shift from the absolute tenses used in the reported utterance of DS to the corresponding relative tenses used in the reported utterance of IS.

\footnotetext{
13 This interpretation - and visualization - of the mechanisms involved in backshift is very different from that offered by Haberland (1986:249). His diagram of tense in IS contains only one time line, on which both the actual speaker's $t_{\mathrm{o}}$ and the represented speaker's $t_{\mathrm{o}}$, as well as the situation described in the reported utterance are situated.
} 
The upper half of Fig. 9 represents the set of absolute tenses used in DS whose reference point is the $t_{\mathrm{o}(\mathrm{RS})}$, viz. the preterite, present perfect, present and future. The lower half visualizes the set of relative tenses (associated with a past reporting clause), whose reference point is the past time of orientation within the intensional domain, backshifted from $t_{\mathrm{o}(\mathrm{RS})}$. The dotted lines between the two halves of Fig. 9 indicate how these two sets of tenses correspond to each other for expressing anteriority, simultaneity and posteriority vis-à-vis the $t_{\mathrm{o}(\mathrm{RS})}$.

\subsection{Absolute tenses in indirect speech}

Section 4.2 is devoted to the use of absolute tenses in IS. We will first summarize Declerck's position on absolute tenses in IS (section 4.2.1) and will then develop our own alternative view, in which we distinguish intensionally absolute tenses in IS (section 4.2.2) from true absolute tenses, which, though used in an indirectly reported complement clause, are related directly to the actual speaker (section 4.2.3).

\subsubsection{Declerck's position on absolute tenses in indirect speech}

According to Declerck and Tanaka (1996), relative tense, as in examples (19)-(21), is the unmarked option in IS, whereas absolute tense is a marked option which is not always available. The criterion on which, they claim, the use of relative or absolute tense hinges is whether the proposition contained in the reported clause is 'true' according to the represented speaker, in which case relative tense is used, or "is true in a $t_{o}$ world, i.e. in a world that holds at $t_{\mathrm{o}}$ " (Declerck and Tanaka, 1996:287), which sanctions the use of a present absolute tense. It should be remembered here that Declerck recognizes only the $t_{0}$ associated with the actual time of utterance - not the surrogate $t_{\mathrm{o}(\mathrm{RS})}$. Typically, this $t_{\mathrm{o}}$ world is simply the actual speaker's world as in (28), in which both the represented and the actual speaker are committed to the truth of the proposition the earth moves.

Galileo said the earth moves.

In some cases, the $t_{\mathrm{o}}$ world can also be that of the represented speaker at the actual speaker's $t_{\mathrm{o}}$, as in

(Do you know what John said yesterday?) He said I am gay, but that's not true! (Declerck and Tanaka, 1996:287)

In this example, the represented speaker's belief presumably still holds at the actual speaker's $t_{\mathrm{o}}$, and, as the actual speaker denies this proposition, is also contextually relevant at the moment of the utterance.

Declerck and Tanaka consider the use of absolute tenses in IS as the marked option, in the sense that relative tense is always possible, whereas the choice for an absolute tense form "must be well-motivated, and it is subject to certain restrictions" (1996:186). In their view the absolute tense form is "in most cases" interpreted 'transparently', i.e. as a proposition to whose truth the actual speaker is committed, as in (28). Non-transparent absolute tenses, which convey the represented speaker's belief, but as contextually relevant to the actual speaker's world (e.g. (29)) are claimed to form the marked case and to be quantitatively restricted, requiring rather exceptional contextual conditions.

This description makes certain predictions about the quantitative distribution of relative and absolute tenses in IS. To verify these predictions and get a first empirically-based idea of the quantitative distribution, Vandelanotte (2005:110-112) analysed and quantified a random sample of 500 sentences with said that extracted from the COBUILD Corpus. The search was executed through the different subcorpora and thus includes examples from informal, spoken language as well as from more formal registers. The tense patterns in the 500 tokens were analysed as either 'relative tense', 'absolute past tense', 'absolute present tense within actual speaker's world', ‘absolute present tense associated with represented speaker'. The main quantitative findings are visualized in Table 1.

The most remarkable finding is that relative tense is not as dominant as might have been expected: nearly half of the tokens in this sample have absolute tense. Within the cases of absolute tense, more than half are present tense, but absolute past tense examples form an important minority of about 40\%. Moreover, contrary to Declerck and Tanaka's (1996) predictions, the case in which it is not the actual speaker's $t_{0}$ world in terms of which the absolute present tense can be interpreted turns out to be the unmarked one, at least as far as frequencies go. This type accounts for $82 \%$ of the absolute

Table 1

Relative and absolute tense in a sample of 500 said that sentences (data from Vandelanotte, 2005).

\begin{tabular}{|c|c|c|c|}
\hline & \multicolumn{3}{|c|}{ Data set considered } \\
\hline & All & Absolute & Absolute present \\
\hline \multirow[t]{2}{*}{ Relative } & 274 & & \\
\hline & $54.8 \%$ & & \\
\hline \multirow[t]{2}{*}{ Absolute (total) } & 226 & & \\
\hline & $45.2 \%$ & & \\
\hline Absolute past & 90 & $39.8 \%$ & \\
\hline Absolute present: actual speaker-related & 24 & $60.2 \%$ & $17.6 \%$ \\
\hline Absolute present: represented speaker-related & 112 & & $82.4 \%$ \\
\hline Total number of tokens & 500 & 226 & 136 \\
\hline
\end{tabular}




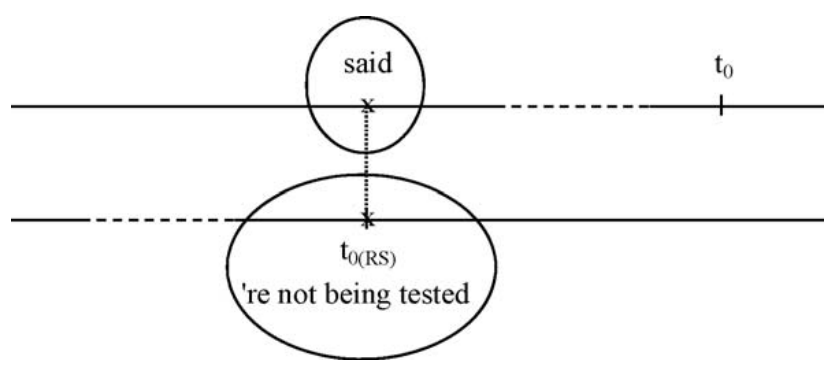

Fig. 10. Intensionally absolute tense in indirect speech.

present tenses. Those examples of absolute presents which are related to the actual speaker's $t_{\mathrm{o}}$ form the less frequent option. While these findings have to be treated with caution, as they can only be regarded as a pilot study, they do suggest the general importance of absolute tenses in IS.

In the following section we will develop an alternative view on the use of absolute tenses in IS. In section 4.2.2, we will argue that absolute tenses in propositions that fall within the represented speaker's intensional domain are related to the $t_{\mathrm{o}(\mathrm{RS})}$, i.e. are intensionally absolute. In section 4.2.3, we will turn to absolute tenses in IS that are related to the actual speaker's, or the real, $t_{\mathrm{o}}$, discussing their general pragmatic-semantic effect, and some contextual instantiations of it.

\subsubsection{Intensionally absolute tense in indirect speech}

The main puzzle posited by past tense forms in IS hinges on the fact that they are potentially ambiguous between a relative and an absolute reading. This is traditionally illustrated with examples such as

$$
\text { Arthur said he was sick. (Huddleston, 1989:395) }
$$

in which the situation of Arthur being sick can be interpreted as either simultaneous or anterior with regard to his talking about it. When one looks at actual corpus data, however, a relative reading is often impossible, as in (31).

\section{The Commerce Department said that factory orders fell by 1.7 percent, reflecting the weaker demand} brought on by the recession. (CB)

Simultaneity between the orders falling and the Commerce Department talking about it is not at stake in (31): fell cannot be interpreted as a backshifted past tense form of a present absolute one related to $t_{\mathrm{o}(\mathrm{RS})}\left({ }^{*}\right.$ The Commerce Department said: "Factory orders fall by 1.7 percent".) This leaves only the reading of fell as an absolute tense, past vis-à-vis the $t_{\mathrm{o}(\mathrm{RS}) \text {. }}$

In section 3, we argued that the absolute tenses found in the represented discourse of DS have to be analysed as taking the $t_{\mathrm{o}(\mathrm{RS})}$ as reference point, i.e. as intensionally absolute. We propose that examples such as (31) and (32) below have to be given a similar analysis, viz. as absolute vis-à-vis the $t_{\mathrm{o}(\mathrm{RS})}$, i.e. intensionally absolute. This is a different, more precise, analysis than the traditional one found in e.g. Boogaart (1996), which simply says that the situation in the reported clause precedes that of the reporting clause. Example (32) is a particularly clear illustration from spoken discourse of a reported proposition for which the represented speaker is responsible.

Erm my little boy's now seven and he will be one of the first to be tested and we went to a meeting today at school er for the head teacher to explain what was being done and he said that they're not being tested as such but we were told to take it as an assessment. (CB)

Contextual clues in (32) make it clear that the proposition in the reported utterance cannot be ascribed to the actual speaker, a parent who does believe that the children will be tested, but falls within the represented speaker's intensional domain, the head teacher who presents it as if they won't be. Hence, are not being tested clearly has the $t_{\mathrm{o}(\mathrm{RS})}$ as reference point, with regard to which it is future. The progressive present are not being tested conveys a future plan under the control of the represented speaker (Declerck, 1991b:90). The deictic structure of the tense use in (32) can, analogously with the representation in Fig. 5 for DS, be represented as in Fig. 10.

As shown by Vandelanotte's (2005) quantified pilot study of IS examples with said that, intensionally absolute preterites are by no means uncommon and account for the larger part of absolute tense use in IS. A possible reason for this might lie in the informational redundancy of backshifted past perfect tenses, which express the anteriority vis-à-vis the shifted $\overleftarrow{t_{\mathrm{o}(\mathrm{RS})}}$ in the tense form itself. The pastness of the reported utterance is clear enough when an absolute past is used in an example such as (31) because there are enough contextual clues.

\subsubsection{True absolute tense in indirect speech}

The IS mode can also be manipulated by the actual speaker so as to incorporate a proposition as relating to the actual ground. A type of context in which this happens very clearly is when the reported utterance is 'factive' (Kiparsky and 
Kiparsky, 1971), i.e. presupposed true by the actual speaker. ${ }^{14}$ Kiparsky and Kiparsky (1971:162-163) pointed out that factive complements, while also allowing the 'sequence of tenses', readily take absolute tenses, as in

$$
\text { John grasped that the earth is (was) flat. (Kiparsky and Kiparsky, 1971:162) }
$$

The status of the proposition being presupposed true by the actual speaker is particularly clear when its truth is not apparent to the represented speaker (or knower), as in examples such as (34) and (35), which represent not knowing.

(34) The defence industry sector has always been such a closed circle that even Mr Gorbachov admitted a couple of years ago that he did not know how much the Soviet Union spends annually on arms. (CB)

$$
\begin{aligned}
& \text { No, he hadn't heard of benzene. He didn't know that it is a potent carcinogen. } \\
& \text { (http://www.sarai.net/publications/readers/02-the-cities-of-everyday-life/17cancer.pdf) }
\end{aligned}
$$

In these examples the surrogate $t_{\mathrm{o}(\mathrm{RS})}$ is not activated and the proposition is straightforwardly related to the real $t_{o}$ of the actual speaker. In short, factive complements readily take true absolute tenses whose reference point is the real $t_{o}$ because the actual speaker is committed to their propositional content.

\section{Conclusion}

The main point made in this article is that, to elucidate tense use in the various modes of reported speech, the intensional

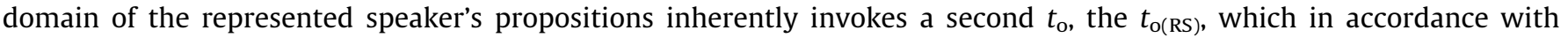
Langacker's (1985) notion of the surrogate ground can also be referred to as the surrogate $t_{\mathrm{o}}$. In the diagrammatic representations of tense developed by Declerck $(1997,2006)$ this entails inserting a second time line with its own $t_{\mathrm{o}}$ in the represented speaker's intensional domain.

In direct speech (DS), we have argued, the surrogate $t_{o(\mathrm{RS})}$ is most obvious. In an example such as (36).

$$
\begin{aligned}
& \text { She said: "I'm looking for printing paper". (http://www.authorsden.com/visit/viewblog.asp?authorid=47838\&m } \\
& =1 \& y=2007 \& b l o g i d=19088 \text { ) }
\end{aligned}
$$

' $m$ looking clearly should not be referred to the actual speaker's utterance time-in which case it would be situated later in time than said - but to the represented speaker's $t_{\mathrm{o}}$ (the $t_{\mathrm{o}(\mathrm{RS})}$ ), in the surrogate ground. This surrogate $t_{\mathrm{o}}$ is evoked by the fictive re-enactment of the original utterance by the actual speaker at the (real) $t_{\mathrm{o}}$. While located co-temporally with the described speech act (past said in 36), the surrogate $t_{\mathrm{o}}$ is fictively 'current', sanctioning the use of absolute tenses, e.g. ' $m$ looking in (36). We have called such tenses intensionally absolute, because they are situated in the intensional domain of the represented speaker's propositional contents and illocutions.

Indirect speech (IS) features, firstly, backshifted relative tenses, for which the contribution of the surrogate $t_{o}$ has been neglected so far. By contrast, for person deixis in IS, the conceptualizer of the reported clause has been invoked to explain, for instance, the use of logophoric reflexives (Van Hoek, 1997:176). We have argued that relative tense in IS likewise requires us to invoke the surrogate $t_{o}$, which, because of the deictic dependence of the reported clause on the matrix, shifts to a past time of orientation.

$$
\text { I said he must forget it ever happened. (CB) }
$$

Mr Cooke said he would call about 25 witnesses. (CB)

The use of performative (Nuyts, 2005) modal must with a relative past sense can only be explained as expressing a simultaneous relation with the backshifted surrogate $t_{0}$. More generally, in any example of IS with relative tense, the relation, for instance that of posteriority in (38), is not to the temporal location of the matrix as such, but to the surrogate $t_{o}$ invoked in it. Hence, we characterize backshifted tenses as intensionally relative.

Further options open to IS include both intensionally absolute tenses as in DS and true absolute tenses, as in (39).

\footnotetext{
${ }^{14}$ In the literature it has been proposed that typical factive complements are structurally different from reported speech complements, as reflected by their different syntactic behaviour (Halliday, 1985:243-244; Langacker, 1991:34-35). Factive clausal complements have more nominal properties than represented speech complements: they can be prefaced by NPs such as the fact and referred to by it and also manifest the word order of ordinary direct objects. Represented speech complements cannot be prefaced by nominals (?He said the statement he was looking for printing paper), are replaced by the clausal substitute so and do not have all the word order properties of direct objects (Vandelanotte and Davidse, 2009:783). Factive clausal complements behave more like real direct objects not only structurally but also semantically, as they refer to propositions "being manipulated, evaluated and commented on" (Langacker, 1991:35). However, to us there does not appear to be any direct relation between the distinct structural properties of factive complements and their propensity to take true absolute tenses. The main motivation seems to be semantic-pragmatic and also applies to factive complements in syntactic environments that are less clearly nominal such as 'extraposed' clauses, e.g. it was important that it is an energy efficient fridge freezer (http://www. ciao.co.uk/Bosch_KDL_1952_5155871).
} 
She did not know that if the menstruating woman becomes pure before Fajr she has to pray Maghrib and 'Isha'. (www.islam-qa.com/en/ref/117671)

In the "semantically factive" (Kiparsky and Kiparsky, 1971:147) example (39), the represented knower she is not even aware of the proposition, presupposed to be true by the actual speaker. Hence, her intensional domain with its surrogate $t_{o}$ is not activated and the proposition relates directly to the actual speaker.

In this article we have thus set out the main notions and mechanisms that seem necessary for the analysis of tense in represented speech to do justice to its conceptual complexity and formal specificity. The proposed mechanisms need to be developed further and applied to more contexts. Topics that need further study include: tenses in IS with reporting clauses in other tenses than the past, tensing of modal auxiliaries in IS, and tenses in factive complements. As well, tense use in the reporting modes in between DS and IS such as free indirect speech will have to be studied. It is only after sustained analysis of all these areas that a systematic description of tense use in represented speech can eventually be hoped to be arrived at.

\section{References}

Boogaart, Ronny, 1996. Tense and temporal ordering in English and Dutch indirect speech. In: Janssen, T.A.J.M., van der Wurff, W. (Eds.), Reported Speech: Forms and Functions of the Verb (Pragmatics \& Beyond New Series 43). Benjamins, Amsterdam/Philadelphia, pp. $213-235$.

Brinton, Laurel, 2008. The Comment Clause in English: Syntactic Origins and Pragmatic Development. Cambridge University Press, Cambridge.

Comrie, Bernard, 1986. Tense in indirect speech. Folia Linguistica 20 (3-4), 265-296.

Coulmas, Florian, 1986. Reported speech: some general issues. In: Coulmas, F. (Ed.), Direct and Indirect Speech. Mouton de Gruyter, Berlin, pp. 1-28.

Declerck, Renaat, 1991a. Tense in English: Its Structure and Use in Discourse. Routledge, London.

Declerck, Renaat, 1991b. A Comprehensive Descriptive Grammar of English. Kaitakusha, Tokyo.

Declerck, Renaat, 1997. When-Clauses and Temporal Structure (Routledge Studies in Germanic Linguistics). Routledge, London/New York.

Declerck, Renaat, 1999. Remarks on Salkie and Reed's (1997) ‘pragmatic hypothesis' of tense in reported speech. English Language and Linguistics 3 (1), 83116.

Declerck, Renaat, in collaboration with Susan Reed and Bert Cappelle, 2006. The Grammar of the English Verb Phrase, vol. 1: The Grammar of the English Tense System: A Comprehensive Analysis (Topics in English Linguistics 60-1) Mouton de Gruyter, Berlin/New York.

Declerck, Renaat, Tanaka, Kazuhiko, 1996. Constraints on tense choice in reported speech. Studia Linguistica 50 (3), $283-301$.

Dik, Simon. 1997. The Theory of Functional Grammar. Part 2. Complex and Derived Constructions. Edited by Kees Hengeveld. Mouton de Gruyter, Berlin Fauconnier, Gilles, 1985. Mental Spaces: Aspects of Meaning Construction in Natural Language. MIT Press, Cambridge (Mass.).

Fludernik, Monika, 2003. Chronology, time, tense and experientiality in narrative. Language and Literature 12 (2), 117-134.

Haberland, Hartmut, 1986. Reported speech in Danish. In: Coulmas, F. (Ed.), Direct and Indirect Speech. Mouton de Gruyter, Berlin, pp. $219-253$.

Halliday, M.A.K., 1985. An Introduction to Functional Grammar. Arnold, London.

Huang, Yan, 2007. Pragmatics (Oxford Textbooks in Linguistics). Oxford University Press, Oxford.

Huddleston, Rodney, 1989. The treatment of tense in indirect speech. Folia Linguistica 23 (3-4), 335-340.

Janssen, Theo A.J.M., 1996. Tense in reported speech and its frame of reference. In: Janssen, T.A.J.M., van der Wurff, W. (Eds.), Reported Speech: Forms and Functions of the Verb (Pragmatics \& Beyond New Series 43). Benjamins, Amsterdam/Philadelphia, pp. $237-259$.

Kiparsky, Paul, Kiparsky, Carol, 1971. Fact. In: Steinberg, D.D., Jakobovits, L. (Eds.), Semantics: An Interdisciplinary Reader in Philosophy, Linguistics, and Psychology. Cambridge University Press, Cambridge, pp. 345-369.

Langacker, Ronald W., 1985. Observations and speculations on subjectivity. In: Haiman, J. (Ed.), Iconicity in Syntax. Benjamins, Amsterdam/Philadelphia, pp. 109-150.

Langacker, Ronald W., 1991. Foundations of Cognitive Grammar. Volume II: Descriptive Application. Stanford University Press, Stanford.

Langacker, Ronald W., 1999. Virtual reality. Studies in Linguistic Sciences 29 (2), 77-103.

Langacker, Ronald W., 2005. Dynamicity, fictivity and scanning. In: Pecher, D., Zwaan, R.A. (Eds.), Grounding Cognition: The Role of Perception and Action in Memory, Language and Thinking. Cambridge University Press, Cambridge, pp. 164-197.

Lyons, John, 1977. Semantics. Cambridge University Press, Cambridge.

McGregor, William, 1997. Semiotic Grammar. Clarendon, Oxford.

Michaelis, Laura, 2006. Time and tense. In: Aarts, B., McMahon, A. (Eds.), The Handbook of English Linguistics. Blackwell, Oxford, pp. $220-243$.

Nuyts, Jan, 2005. The modal confusion: on terminology and the concepts behind it. In: Klinge, A., Müller, H.H. (Eds.), Modality: Studies in Form and Function. Equinox, London, pp. 5-38.

Reichenbach, Hans., 1966 [1947]. Elements of Symbolic Logic. Collier-Macmillan, New York/London.

Rigter, Bob, 1982. Intensional domains and the use of tense, perfect and modals in English. Journal of Semantics 1 (2), $95-145$.

Salkie, Ralph, Reed, Sue, 1997. Time reference in reported speech. English Language and Linguistics 1 (2), 319-348.

Vandelanotte, Lieven, 2002. Tense in speech and thought representation: Some proposed modifications and correlations. Paper presented at the Fifth Chronos Colloquium, University of Groningen.

Vandelanotte, Lieven, 2005. Tense in indirect speech or thought: some proposed modifications. In: Hollebrandse, B., van Hout, A., Vet, C. (Eds.), Crosslinguistic Views on Tense, Aspect and Modality (Cahiers Chronos 13). Rodopi, Amsterdam/New York, pp. 61-75.

Vandelanotte, Lieven, 2006. Speech or thought representation and subjectification, or on the need to think twice. Belgian Journal of Linguistics 20, 137168.

Vandelanotte, Lieven, 2009. Speech and Thought Representation in English: A Cognitive-Functional Approach (Topics in English Linguistics 65). Mouton de Gruyter, Berlin/New York.

Vandelanotte, Lieven, Davidse, Kristin, 2009. The emergence and structure of be like and related quotatives: a constructional account. Cognitive Linguistics 20 (4), 777-807.

Van Hoek, Karen, 1997. Anaphora and Conceptual Structure (Cognitive Theory of Language and Culture). University of Chicago Press, Chicago.

Verstraete, Jean-Christophe, 2001. Subjective and objective modality: interpersonal and ideational functions in the English modal auxiliary system. Journal of Pragmatics 33 (10), 1505-1528.

Verstraete, Jean-Christophe, 2008. The status of purpose, reason and intended endpoint in the typology of complex sentences. Linguistics 46, 757-788.

Kristin Davidse is professor of English linguistics at the University of Leuven (Belgium). She has published in international journals and volumes on the semantics of clause constructions such as existential, ditransitive, cleft, ergative and middle constructions, and, more recently, on emergent grammar and grammaticalization in the NP. She co-founded and for 10 years co-edited the Benjamins journal Functions of Language, and has edited books on functional grammar, the nominative and accusative and grammaticalization. 
Lieven Vandelanotte is associate professor of English linguistics at the University of Namur (Belgium) and affiliated researcher in the Functional Linguistics Leuven research group at the University of Leuven. He has published in international journals and volumes on various topics in English grammar, including prenominal adjectives, modified proper names, and the structural, deictic and semantico-pragmatic properties of different reported speech constructions. He is also interested more broadly in the application of cognitive-linguistic concepts to the study of literary texts, and has recently published the monograph Speech and Thought Representation in English: A Cognitive-Functional Approach (Berlin/New York: Mouton de Gruyter). 